\title{
Cloud Model Design in News Media Convergence Era
}

\author{
Xiao Yu \\ School of Information Engineering, Wuhan Technology and Business University, P. R. China, \\ 430065
}

123189990@qq.com

Keywords: Media convergence; News cloud; Pattern design; Cloud computing

\begin{abstract}
This paper is to promote the traditional media and new media convergence, analysis of the current broadcast TV, radio, television network news cloud and television cooperation, discusses the development promote cloud computing media convergence technology for future research news cloud model, and cloud model designed to provide a reference for the news media converged cloud model-building era.
\end{abstract}

\section{Background}

Central Leading Group comprehensively deepen reforms in August 2014 passed the "Guiding Opinions on Promoting the integration of traditional media and new media development." .The Guidance that promote the convergence of media, traditional media and new media to promote the depth of integration of content, channels, platforms, management, administration and other aspects, and strive to build a number of varied shapes, advanced means new competitive mainstream media [1].To take advantage of media convergence has been a large number of Internet resources, to achieve rapid business innovation and iteration [2].

Many provincial radio and television networks, major efforts to promote cooperation with emerging media technology providers. "News cloud" and "cloud TV" became popular. Cloud and TV news are relying on cloud computing technology applications, but also a lot of TV users cloud concept poorly understood.

\section{The Concept of Cloud}

Cloud, that the concept of cloud computing is Google Inc. in 2006 by the "google101" proposed in the plan. After this, the major computer and networking companies have developed and launched a typical cloud service models and applications, including IBM, Microsoft, Amazon and VM ware and so on. Cloud computing services features an integrated large-scale computing power, distributed computing data with pools of virtualized resources and implement demand charges. The concept of cloud computing is divided into two "cloud" or "cloud storage" and "cloud computing" [3]. "Storage cloud" is actually a large-scale distributed storage system [4]. "Storage cloud" storage interface to third-party users open, users can purchase the appropriate capacity and bandwidth as needed. "Cloud computing" refers to parallel computing and virtualization of resources [5]. Cloud computing proposed a "cloud" application mode, a new computing model and storage model [6]. Cloud computing service model into SaaS (Software as a service), PaaS (Platform as a Service) and IaaS (Infrastructure as a Service). Cloud computing is a style of computing, more storage, services, and the way to spread information. Cloud computing platform management system can be seen as a cloud "Command Center" .Cloud computing system platform management technology enables a large number of servers to work [7].

Today, cloud computing technology applications permeate many areas of social life. Especially the links between the media industry and information industry has countless, in the digital information age, driven by powerful new technologies needed to accelerate the transformation of traditional media, new media and strengthen integration and development. As networking technology, cloud computing technology and triple play to develop, new media development trend presented in all media will function [8]. "Media convergence" represents the computer industry, the 
publishing and printing industry, broadcasting, film industry; different industries are coming and coming together [9]. Cloud computing as an emerging information technologies for the media industry to provide an opportunity.

\section{News Cloud Development Overview}

In simple terms, cloud computing is a distributed network hardware, software, services, and storage resources together to provide on-demand services approach. Broadcasting system has a wealth of information resources, including hardware and software resources, the high cost of these resources, but the resources and resource utilization is not high depreciation of issues outstanding. Cloud computing can integrate existing resources, improve resource utilization. Cloud terminal only needs to configure the lower thin clients, existing low-grade equipment can be utilized, savings broadcasting system. Cloud computing technology allows broadcasting infrastructure and organizational structure within the system has been optimized, cost savings and improve overall operational efficiency, and more important change is the integration of information resources integration caused. Sources of information is not only broadcast television network, but also from things, and other telecommunication networks, e-government network and the Internet integrated network. Flexible resources to Qilu TV "news cloud" for example, in 2010, Qilu Channel launched "Days Ji" full network broadcast system is based networking architecture telecommunications network, the Internet and broadcast television networks integrated deployment system, to achieve anytime, anywhere real-time broadcast, the television news reporter from the mining, audience participation program information provided (UGC) services and information resources of the public sector unified deployment and sharing, in order to supply the internal television use different programs.

Fundamentally change the way news gathering cloud computing environment occurred. Media production and the transition from work digital network environment for work Press cloud platform environments. Data media production work mainly for digital recording, non-linear editing, digital virtual studio, digital broadcast, digital broadcast automatic mode. By news cloud environment is in the news production room computer-aided production, the use of satellite broadcast or cable broadcast using $3 \mathrm{G}$ or $4 \mathrm{G}$ networks broadcast using a mobile terminal or a mobile terminal non-linear editing interviews, production and integration of broadcast production. Cloud computing technology allows programming has greatly improved the effectiveness of the program and the number of quality broadcast. Cloud systems newsgathering news media people put forward higher requirements. Compare the traditional way of news dissemination and news media environment cloud environments, as shown in Table 1.

Table 1 Comparison of traditional media and new media environment

\begin{tabular}{|c|c|c|}
\hline Item & Traditional media environment & News cloud environment \\
\hline Way & $\begin{array}{l}\text { Radio, Television, } \\
\text { Telecommunications, etc. }\end{array}$ & $\begin{array}{c}\text { Cloud TV, Smart phones, } \\
\text { Mobile devices, Computers, etc. }\end{array}$ \\
\hline${ }_{k}$ Networ & $\begin{array}{l}\text { Telecommunications networks, } \\
\text { Cable television, Radio networks, etc. }\end{array}$ & $\begin{array}{l}3 \mathrm{G} \backslash 4 \mathrm{G}, \text { Networking, } \\
\text { Internet, Cloud, etc. }\end{array}$ \\
\hline Style & Passive acceptance of information & Interactive participation \\
\hline
\end{tabular}

Cloud technology has changed the traditional news dissemination. In the traditional media approach, as the main way of public access to information is a passive acceptance of the program through radio and television. With the development of Internet and mobile technologies, the public more active participation to interactive radio and television programs, including through micro-channel interactive platform, microblogging interactive platform to comment, edit text, images, audio, video, etc. to provide information or make personal remarks.

In recent years, the rise of cloud technology has led to the development of cloud-TV industry. Cloud TV has absolutely open cloud platform, cloud services platform which has a wealth of 
television resources, and massive use of software [10]. Cloud television as a news cloud terminal, you need to connect to the service cloud platform provided by the network. Users not only cloud TV television viewers, more of the younger generation of Internet users. They prefer their own interests in accordance with the orientation of the selected program, the initiative to obtain the required information and services, emphasizing the sense of the experience of the program. They believe that the cloud is an Internet television should be extended. Cloud terminal network television as a specific application, and can provide vast amounts of information, high-quality streaming video and real-time news feeds feelings. But cloud television only as a terminal cloud platform, while other devices such as cell phones, computers, tablets may be suitable for different occasions access to the cloud platform.

It includes not only the content they are interested in radio and television programs, but also from a variety of pictures on the internet, text, music, video, film and other media-rich information. A lot of people missed the live television time, but the ability to view all the programs already played video clips in the news cloud platform. Television is no longer limited to the front of the TV watching it live, including simultaneous viewing by vehicle mobile TV terminal, a mobile phone or tablet and other types of terminals. Cloud technology in the media industry represents a new generation of user attitudes and lifestyle needs.

\section{News Cloud Model Design}

Cloud computing by size into a private cloud, community and public clouds. Currently, the system established by the radio and television news cloud should belong to the news industry cloud applications, mainly confined to the internal broadcasting system to establish private cloud services platform. News Cloud audiences and clients for the general public television and Internet users, so the news industry cloud should be between the concept of private and public clouds between. At present, many news network integration cloud does not include a comprehensive integration of e-government network. Internal news broadcasting system can not really edit data in a remote cloud platform for processing, can be downloaded to a local editing device for editing. Therefore, it is in fact no real news cloud model. Cloud-based technology to promote the development of media convergence in thinking and outlook for the future design of the progressive development of information cloud model cloud formation, as shown in Fig. 1.

More Emphasis on the Concept of Service. In cloud computing to promote traditional media and new media integration of the development process, the current development of the press is more technical aspects of cloud applications. However, the cloud concept is the core point of service, rather than just referring to technology. In accordance with the concept of the cloud, the cloud both hardware and network equipment, software or platform as a service to be provided to the user. Our radio and television news so far raised only cloud systems to achieve the integration and sharing of network resources, and these networks and resources within the system is mainly used for radio and television news media people were used in the production, there is no real service for the majority of users. In the era of media convergence, China's media industry not only need to focus on information dissemination, but also need to give more attention to the user's service experience. So as to take advantage of the fierce competition in the international media. Based on cloud technology news television production also need to consider how to provide users with a richer experience feelings.

More Emphasis on the Concept of Service. In cloud computing to promote traditional media and new media integration of the development process, the current development of the press is more technical aspects of cloud applications. However, the cloud concept is the core point of service, rather than just referring to technology. In accordance with the concept of the cloud, the cloud both hardware and network equipment, software or platform as a service to be provided to the user. Our radio and television news so far raised only cloud systems to achieve the integration and sharing of network resources, and these networks and resources within the system is mainly used for radio and television news media people were used in the production, there is no real service for the majority of users. In the era of media convergence, China's media industry not only need to focus on 
information dissemination, but also need to give more attention to the user's service experience. So as to take advantage of the fierce competition in the international media. Based on cloud technology news television production also need to consider how to provide users with a richer experience feelings.

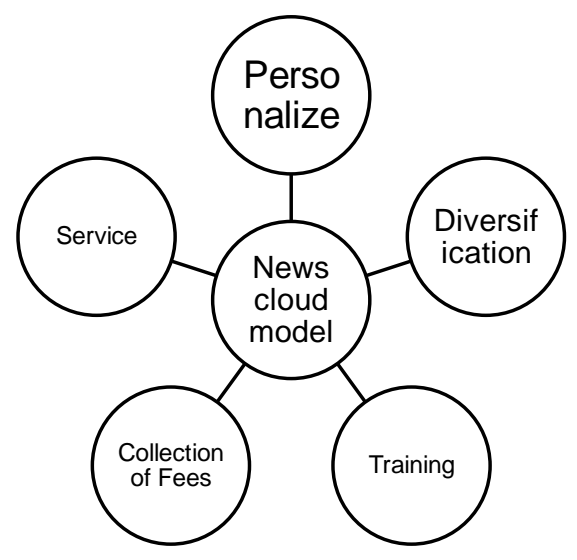

Figure 1. News cloud model

Media Should Be More Emphasis on Personal Development. In the future, the broadcasting system uses cloud computing technology to provide powerful computing capability to provide users with anytime, anywhere service. News programs should be more emphasis on personalized and customized news and advertising information push. The media should provide a more convenient on-demand, comments, subscriptions and watch the timing and other personalized way, include the ability to view the user's personal account on a variety of media information or watch programs. If a user has searched a field program in the channel, it will be in the next boot interface displays the latest news and program information in the field. For example, if the user has recently watched sports news, you can display the latest sports news in the recommendation section. If the user has recently watched mother and child programs, maternal and child can push information and advertising in the recommended section.

Media Interactive Mode Should Be More Diverse. Interactive mode is based on the current TV show is relatively simple, mainly in micro-channel micro-blog reviews based. Media convergence should be innovative interactive media and the strengthening of public participation. The use of cloud computing technology and networking technology, the public can phone or GPS positioning intelligent information collection participate in interactive programs. Comment comments need to establish a program for the credit system, you can set up news sites integral management, encourage more users to participate in the program.

Future News Cloud Services Need to Establish Charging Mode. Another feature of cloud computing is on-demand charges. At present, fees in the country there is no uniform standard. US network information provided by Apple is a service fee by success stories. How our news and advertising business conduct issue press service charge to be further explored in the news cloud environment. You can watch news programs on different terminals. TV viewing costs more unified, but the use of a computer, phone or tablet to watch a program on the network charges a bit confusing. Establish charging cloud-based media service is the key to profitability. In addition, news cloud should provide a variety of payment methods, such as bank card payment, or micro-channel pay Alipay payments.

Strengthen Vocational Training and College Media Professional Vocational Skills Training of New Media. With the media industry to bring cloud technology to improve time efficiency and economic efficiency, and also to the media workers raised new challenges, vocational training media workers is very important. Media workers need to keep learning, to strengthen the practical ability in information technology. College students should recognize media convergence trends of the times strengthen practical ability and network technology skills development. 


\section{Conclusion}

In short, cloud technology in promoting media convergence is still in the early stages of development, the future still need to continue thinking and optimization of media convergence model in the new technology exploration and practice news clouds and cloud TV, the traditional media and new media can complement each other, complementary advantages.

\section{References}

[1] C. Y. Zhu, X. Y. Liu and H. Yang: How to shape a new era of media convergence mainstream media and modern communication systems. Journalism Bimonthly, Vol.128 (2014), p9-15. (In Chinese)

[2] Q. W. Dong: The Key Factors of the PaaS Layer for a Converged Media Cloud Platform .Radio \& Television Information, Vol.282 (2015), p 30-33. (In Chinese)

[3] Q. Li, X. Zheng: Current Situation Survey cloud computing. Computer science, Vol.38 (2012), p 32-37. (In Chinese)

[4] J. X. Zhang, Z. M. Gu and C. Zhen: Cloud computing research progress. Application Research of Computers, Vol.27 (2010), p29-433. (In Chinese)

[5] Q. Chen, Q. N. Deng: Cloud computing and key technology. Computer Application, Vol.29 (2009), p2562-2567. (In Chinese)

[6] G. Li, D. Tang and Y. R. Wang: Analysis of the Concept of Cloud Computing and Its Reliability. Modern Computer, Vol.23 (2014), p39-41. (In Chinese)

[7] W. Fang, X. Z. Wen, W. B. Pan and S. J. Xue: Cloud computing: Conceptions, key technologies and application. Journal of Nanjing University of Information Science and Technology: Natural Science Edition, Vol.4 (2012), p351-361. (In Chinese)

[8] X. C. Yu, P. C. Huang: Four dimensions of new media development at full media context. Editorial Friend, Vol.8 (2012), p70-73. (In Chinese)

[9] L. Sun, L. Zhang: Construction of New Mainstream Media under Condition of Media Convergence. Chongqing social sciences, Vol. 242(2015), p80-86. (In Chinese)

[10]X. Li: Full TV Media Cloud Technology Exploration Prospects. Technology Innovation and Application, Vol.22 (2016), p105-106. (In Chinese) 